TRANSPORT AND CLIMATE CHANGE: SIMULATING THE OPTIONS FOR CARBON REDUCTION IN LONDON

\author{
Dr Robin Hickman \\ Transport Studies Unit, University of Oxford; Halcrow Group, London \\ Olu Ashiru \\ Takedo International; Halcrow Group, London \\ Professor David Banister \\ Transport Studies Unit, University of Oxford
}

\begin{abstract}
Transport is a major user of carbon-based fuels, and it is increasingly being highlighted as the sector which contributes least to $\mathrm{CO} 2$ emission reduction targets. This paper reports on the findings of the VIBAT London study (www.vibat.org) which considers the role of the transport sector in reducing $\mathrm{CO} 2$ emissions in London.
\end{abstract}

The analysis develops a transport and carbon simulation model (TC-SIM) for London. Within this, users are able to consider the implementation of a series of potential policy packages - low emission vehicles, alternative fuels, pricing regimes, public transport, walking and cycling, strategic and local urban planning, information and communication technologies, smarter choices, ecological driving and slower speeds, long distance travel substitution, freight transport, and international air. They can select variable levels of application to help achieve headline $\mathrm{CO} 2$ emission reduction targets. The roles of carbon rationing and oil prices are also considered. TC-SIM can be played in different user modes: as 'free riders', 'techno-optimists', 'enviro-optimists', 'complacent car addicts' and other typical travel market segments, including a 'free role'. Game playing or scenario testing such as this helps to highlight perceived levels of homogeneity of views within certain cohorts, the development of entrenched positions and the likely success in achieving objectives.

The paper develops various policy packages, scenarios and pathways aimed at reducing transport $\mathrm{CO} 2$ emissions. It argues that strategic $\mathrm{CO} 2$ emission reduction targets are very ambitious relative to current progress, and that we need to act more effectively across a wide range of policy mechanisms, with a 'high intensity application' of many of the options, to get near to achieving these targets. A critical issue here will be in communicating and gaining greater 'ownership' of future lifestyle choices with stakeholders and the public, and participation tools such as TC-SIM could become increasingly important in this area.

Keywords - Transport, Climate Change, Carbon, Scenarios, Policy Packages, London 


\title{
TRANSPORT AND CLIMATE CHANGE: SIMULATING THE OPTIONS FOR CARBON REDUCTION IN LONDON
}

\author{
Dr Robin Hickman \\ Transport Studies Unit, University of Oxford; Halcrow Group, London \\ Olu Ashiru \\ Takedo International; Halcrow Group, London \\ Professor David Banister \\ Transport Studies Unit, University of Oxford
}

\section{Introduction}

Climate change and projected rises in greenhouse gas (GHG) emissions pose a major challenge for the UK and the world. Population growth, increased average incomes and material consumption mean that reducing emissions becomes very difficult. The transport sector contributes around $25 \%$ carbon dioxide (CO2) emissions in the UK, yet remains the major under-performing sector in contributing to emissions reductions. Trend-breaking futures are required to help mitigate and adapt to the potential impacts of global warming.

Many authors (the International Panel on Climate Change, IPCC, 2007; Stern, 2009; and others) give stark warnings. An overwhelming body of scientific evidence now clearly indicates that climate change is a serious and urgent issue. The concentration of atmospheric $\mathrm{CO} 2$ has increased from a pre-industrial value of around $280 \mathrm{ppm}$ to $379 \mathrm{ppm}$ in 2005, with levels of CO2 emissions expected to rise to 550 ppm by 2050 without immediate intervention ${ }^{1}$. Atmospheric $\mathrm{CO} 2$ concentration increased by only 20 ppm over the 8,000 years prior to industrialisation, with multi-decadal to centennialscale variations less than $10 \mathrm{ppm}$ that were most likely due to natural processes. However, since 1750, CO2 concentration has risen by nearly $100 \mathrm{ppm}$. The annual CO2 growth rate was larger during the last 10 years (the 1995-2005 average is 1.9 ppm p.a.) than it has been since continuous direct atmospheric measurements began (the 1960-2005 average was $1.4 \mathrm{ppm}$ p.a.). The rate of atmospheric CO2 concentration growth (now 2-3 ppm p.a.) means that we are likely to hit the $400 \mathrm{ppm}$ threshold within 10 years (from 2005) and the 450 ppm threshold within 35 years (2005-2040). Even the more conservative estimates of atmospheric CO2 concentrations are likely to cause climatic difficulties. A rise of 2 or 3 degrees in surface temperature resulting from an increase in $\mathrm{CO} 2$ concentrations to $450 \mathrm{ppm}$ will lead to fewer cold days and nights, more frequent hot days and nights (virtually certain); warm spells, heat waves, heavy precipitation events (very likely); areas affected by drought increase, intense tropical cyclone activity and increased incidence of extremely high sea levels (including tsunamis) (likely) (IPCC, 2007).

The IPCC estimates that most $(>50 \%)$ of the observed increase in global average temperatures, since the mid-20th century, is very likely (defined as a $90 \%$ probability) to have been caused by anthropogenic activities. Eleven of the last 12 years (1995 to 2006), the exception being 1996, rank among the 12 warmest years on record since 1850. Within this global picture, transport is playing a major and increasing role. It

\footnotetext{
${ }^{1}$ The target levels in the EU for the stabilisation of emissions in 2050 are $550 \mathrm{ppm} \mathrm{CO}_{2} \mathrm{e}$ or $450 \mathrm{ppm} \mathrm{CO}_{2}$. The higher figure includes all greenhouse gas emissions, of which $\mathrm{CO}_{2}$ emissions are the most important.
} 
relies largely on a single carbon source, petroleum, which supplies $95 \%$ of the energy used in world transport. In 2004, transport was responsible for $22 \%$ of world energy related greenhouse gas emissions and its rate of increase is faster than any other energy using sector (IPCC, 2007). It seems essential that transport should contribute much more substantially to reduction targets for $\mathrm{CO} 2$ emissions.

A number of authors have examined the potential role of transport in a carbon constrained future through global analysis (Ewing et al, 2008; Schäfer et al, 2009; Sperling and Gordon, 2009; Yang et al, 2009). Others have considered transport as part of wider energy reduction futures (Mackay, 2009), and there is an earlier literature on achieving sustainable transport, for example, the OECD EST study (OECD, 2000) and the EU-POSSUM project (Banister et al, 1997). Hickman and Banister (2007) consider policy pathways at the UK level. All suggest the need for radical trend-breaks in terms of moving towards sustainable transport futures.

London provides a complementary case study to this analysis. Per capita transport emissions, particularly in inner London, are low relative to many western industrialised international city standards, and are lowest of all urban areas in the UK. There are already impressive efforts to fund and develop public transport, walking and cycling, and integrate urban and transport planning.

This paper draws on findings from the VIBAT London ${ }^{2}$ study (Visioning and Backcasting for Transport in London). It uses London as a case study and develops a simulation model of the city to test potential future scenarios for different levels of application of different policy packages. The analysis adds to the developing debate on low carbon transport pathways at the city level by quantifying the likely impacts of a wide range of interventions, and outlining potential future scenarios of application. The baseline and projections are considered with respect to $\mathrm{CO} 2$ reductions and transport, before outlining the range of policy measures available. These are assembled into packages to ensure consistency and effectiveness so that the potential benefits can be made complementary. Various role or game playing options are then presented so that a range of different potential stakeholder viewpoints can be compared in terms of their involvement and concern over achieving the overall reduction targets for transport in London. It is noted that these different 'player roles' are likely to select different options according to their own set of perceptions and rules. Two other critical issues are raised: how to deal with aviation, and the role of oil prices and carbon credits. Finally, some conclusions are drawn on optimised packaging and the need for the development of simulation tools that can effectively engage a wider cohort of the population in the debate over achieving sustainable mobility.

\section{The Role of the Transport Sector}

London is aiming to become a 'model' sustainable city that can combine population growth with economic prosperity and a fair society, but at the same time reduce its carbon emissions. Current levels of emissions (2006) in London are around $44 \mathrm{MtCO} 2$ (million tonnes of carbon dioxide). Achieving large reductions in carbon emissions, whilst retaining economic and quality of life goals, is likely to be difficult, even with a

\footnotetext{
${ }^{2}$ More detailed papers from the VIBAT London study (Hickman et al, 2009b) can be found at www.vibat.org. The study was funded under the UrbanBuzz Programme, www.urbanbuzz.org.
} 
static population and employment base. Add in large population and economic growth and the task to reduce aggregate emissions becomes considerable. London's population is expected to grow by $23 \%$ to 9 million in 2050 from 2006 levels, and the economy by between $100 \%$ and $150 \%$ over the same period (GLA, 2009).

A large amount of strategic forward planning and analysis has already been carried out by the public agencies in London. Transport for London has produced Transport 2025 (T2025) (TfL, 2006) and the Mayor's Transport Strategy (TfL, 2009). The Greater London Authority has produced the London Plan (GLA, 2009) and Climate Change Action Plan (CCAP) (GLA, 2007). The headline target adopted for London is a $60 \%$ reduction in CO2 emissions by 2025 across all sectors on 1990 levels (CCAP, 2007) this is a very ambitious target (Table 1 and Figure 1).

\section{INSERT TABLE 1}

\section{INSERT FIGURE 1}

Within London, the transport sector accounts for $22 \%$ of ground-based transport $\mathrm{CO} 2$ emissions (9.6 MtCO2). This figure rises dramatically if aviation is included - the methodology used within CCAP is that half of emissions from all flights landing at London airports (Heathrow and City Airport) are allocated to London residents' emissions. This results in aggregate transport emissions rising to $48 \%$ (Figure 2). Within the transport sector, car-based CO2 emissions dominate (at 49\%) and road freight (23\%) (Figure 3).

\section{INSERT FIGURE 2}

\section{INSERT FIGURE 3}

There are interesting comparisons to be made between areas in London and in the UK. The transport sector, for London as a whole, performs well because of the high usage of public transport. There are, however, large differentials within London. The highest emitters are found in the more car-dependent suburbs - Bromley, Bexley, Barnet and Hillingdon. Even here, $\mathrm{CO} 2$ emissions perform well relative to the rest of the country, on a par with a mid-ranking smaller town in the UK, such as Stockport or York.

The lowest emitters in London are found in the City of London and the boroughs with good public transport links (Islington, Camden, Hammersmith and Fulham, Ealing) and in East London where lower incomes have a stronger influence (Tower Hamlets). These locations can be viewed as existing 'good practice' examples of low carbon transport lifestyles, achieving per capita emissions of a fifth or less relative to the higher emitters. Achieving further [deep] emissions reductions in London may hence be difficult due to the low base in some locations. The low level of $\mathrm{CO} 2$ emissions from transport in London merits further research as it probably relates to many factors, including incomes and other socio-economic characteristics, attitudinal and cultural/consumption characteristics, urban structure and the level of transport infrastructure (high quality public transport facilities). The relative importance of each of these interrelated factors is as yet unclear, but clearly context is important in determining targets.

\section{INSERT TABLE 2}


The policy response at the UK level has been slow in development (Banister and Hickman, 2009). Top-down target setting has evolved to promote more stringent policy targets, but in all cases international aviation is excluded:

- Over 15 years ago, the Royal Commission on Environmental Pollution recommended the adoption of a $60 \%$ CO2 emission reduction target by 2050 , using a 1990 base (RCEP, 1994 and 1997);

- The Kyoto Protocol (1997) seeks to achieve "stabilisation of greenhouse gas (GHG) concentrations in the atmosphere at a level that would prevent dangerous anthropogenic interference with the climate system." The UK Kyoto commitment is a $12.5 \%$ reduction in six GHG below 1990 levels over the period 2008-2012. The Protocol expires in 2012 and negotiations are ongoing for a replacement agreement (including the COP15 negotiations in Copenhagen in December 2009);

- The UK domestic target was originally for a $20 \%$ reduction of $\mathrm{CO} 2$ emissions below 1990 levels by 2010 (DETR, 2000). A "pathway towards" a 60\% reduction of $\mathrm{CO} 2$ emissions by 2050 was then endorsed by the UK Government (DTI, 2003).

- Most recently the UK Climate Change Act (2008) includes a statutory CO2 reduction target of $80 \%$ by 2050 (on 1990 levels), and also intermediate targets. Sector-based contributions and interim budgets are also being allocated.

None of the targets will be met without the purchase of permits through the EU Emissions Trading Scheme. All governments are finding it enormously difficult to achieve the target levels set, with greater clarity on technological possibilities, but less understanding of the difficulties in encouraging lifestyle changes.

The striking feature of the current discourse is therefore the difficulties for future achievement of targets. The gap between BAU projections and the adopted emissions reduction targets cannot be reconciled, and the difficulty of achieving this scale of trend-break is apparent.

\section{Modelling Approach and Simulation of Scenarios}

A transport and carbon simulator (TC-SIM) has been developed in the VIBAT London study to help explore the packaging of policy options available to help reduce transport $\mathrm{CO} 2$ emissions. Such participation tools can help broaden the debate in the decisionmaking process. It includes a scenario building and policy discussion platform, with a spatial base, around which decisions in relation to possible future scenarios and policy packages can be made. It allows a transparent comparison of different scenarios against quantified $\mathrm{CO} 2$ impacts. Figure 4 shows the playing screen for TC-SIM. The 12 policy packages (PP) considered cover:

- PP1: Low emission vehicles;

- PP2: Alternative fuels;

- PP3: Pricing regimes;

- PP4: Public transport; 
- PP5: Walking and cycling;

- PP6: Strategic and local urban planning;

- PP7: Information and communication technologies (ICT);

- PP8: Smarter choice soft measures;

- PP9: Ecological driving and slower speeds;

- PP10: Long distance travel substitution;

- PP11: Freight transport;

- PP12: International air travel.

\section{INSERT FIGURE 4}

The modelling behind TC-SIM has been developed to allow quantification of the potential impacts of a range of policy interventions in multiple combinations. It uses and combines a variety of data sources, including London Travel Survey (LTS) highway modelling and Railplan public transport runs, a spreadsheet of transport $\mathrm{CO} 2$ emissions developed by TfL, a vehicle fuel penetration spreadsheet developed for Defra and a number of other databases. Each policy package can be selected at a variety of levels of intensity of application - typically a 'low', 'medium' or 'high' level of application. Modelling outputs from the analysis in T2025 are generally used to assess likely impacts, particularly Scenario 1 Reference Case and Scenario 4 Full Programme (Annex 1 provides a list of schemes within each scenario), with additional modelling developed to estimate the impacts of interventions not considered within T2025. A more detailed commentary of the model specification is found in a background note to the VIBAT London project (Ashiru et al, 2009).

The following system architecture is used within TC-SIM:

- A Flash based active-x graphical user interface;

- Data input and underlying model assumptions provided by means of a comma separated text file and an $\mathrm{xml}$ file;

- Comma separated text file contents are provided by a detailed spreadsheet based Transport Carbon Calculator (TC-SIM CALC).

The assumption in terms of background traffic growth is that traffic grows year on year as an extrapolation of recent trends. Relative to the rest of the UK, London is different in that traffic growth has been limited in recent years, and it appears to have reached the top of the "S" curve of traffic growth. The BAU application is assumed to be the Reference Case (Scenario 1) in T2025 (TfL, 2006). This broadly represents the current fully funded investment strategy for TfL (2006-2009) and is thus the best representation of current BAU. It does however represent a significant amount of funding approximately £2-7 billion per annum to 2025 (TfL, 2006).

TC-SIM draws to a certain extent on attitudinal theory, a field being increasingly applied to transport planning (Shiftan et al, 2008; Anable, 2005). This helps us to acknowledge that there are different viewpoints and attitudinal cohorts in the travel market and approaches within policy making. A single policy response is unlikely to encourage changed behaviour in all users. The travel market is thus probably best simplified and 
understood by segmentation into coherent groups that share similar characteristics. TC-SIM is therefore designed to be played under a 'free role' or in different user modes, such as 'free riders', 'techno optimists', 'enviro-optimists', 'complacent car addicts' and 'concerned realists'. Six different types of player have been identified (Figure 4) and four of these are described here. The policy choices under each user role are restricted to represent the likely viewpoints for each cohort. For example, a techno-optimist performs well on the technological options (low emission vehicles, alternative fuels, ICT) but poorly on the behavioural options. Game playing or scenario testing is then undertaken to illustrate particular views within certain cohorts and entrenched policy positions and their likely success in achieving objectives. Game theory (originally developed by Von Neumann and Morgenstern, 1944; and others) has also been applied to transport planning, but mainly in modelling and route choice (Bell, 2000; and others); it has seldom been used in transport futures studies and strategy development.

\section{Results from TC-SIM with the Different User Types}

TC-SIM has been widely used with a range of different users, and their experiences and comments have been used to modify the user interface and the packaging process. The different outcomes from four of the six user types are outlined below, together with a commentary on the packages used in each case and the levels of implementation. As can be seen, it is difficult to achieve the scale of change necessary to reach the target set (a $60 \%$ reduction on 1990 levels of $\mathrm{CO} 2$ by 2025).

\subsection{Free Riding}

The need to act across a wide range of policy areas is well appreciated in London, and many of the policy areas are well developed. Achieving the ambitious targets that have been adopted in London may require even more intensive application of the policy measures already being considered. "Application", in this context, is perceived as strategic policy direction (governmental), scheme implementation (governmental, private sector) and take up (the public). These are all inextricably linked, but often work in a poorly integrated manner.

The free rider role illustrates the cohort of population (or the policy standpoint) believing that a reduction in $\mathrm{CO} 2$ emissions will result if we achieve modest gains from technology and behavioural change. Despite relatively high concern for the negative effects of car use, this cohort is reluctant to sacrifice current lifestyles for the sake of the environment. They need much more persuasion that reducing their car use will make much difference to carbon emissions, as they believe others will not reduce their car use (they have concerns with efficacy). They perceive many problems in using public transport, walking and cycling on a mass scale. They see a small increase in vehicle $\mathrm{km}$ (from present levels), with moderate gains from technology, as the best way to achieve $\mathrm{CO} 2$ reduction targets.

Figure 5 and Table 3 show the result when the free rider role is played. Progress towards the headline target is not made to any great degree - resulting in an aggregate $4.5 \%$ contribution to the VIBAT London target.

INSERT FIGURE 5

INSERT TABLE 3 
Comment - There is a general reluctance with this cohort to get involved in many of the policy packages available, and effectively only a limited change is even contemplated with some positive reaction to more efficient and low emissions vehicles. This approach would not make any real contribution to the targets, and the outcomes are broadly similar to no change on existing patterns of travel in London.

\subsection{Techno-Optimism}

The techno-optimist role is used to illustrate the cohort of population (or policy standpoint) that focuses on technological options to reduce $\mathrm{CO} 2$ emissions. PP1 low emission vehicles, PP2 alternative fuels and PP7 ICT are the policy packages with most technological focus. It could be argued that this user role is broadly illustrative of policy development at the UK level. Only a narrow range of policy measures are being employed here, including voluntary car emission agreements, some limited fiscal intervention, a renewable fuels target and other 'low intensity' application of measures, such as freight distribution and soft measures. Within the simulation, the assumption is made that traffic grows year on year as an extrapolation of recent trends.

Figure 6 illustrates the techno-optimist role played to a very ambitious, high intensity level of application, and Figure 7 and Table 4 to a less ambitious and low level of application. The result for a low level application of PP7 is a contribution reduction in $\mathrm{CO} 2$ of just $6.2 \%$ of the total target, as compared with the high ambition level of $24.5 \%$. This range explores the potential for vehicle technology to achieve $\mathrm{CO} 2$ reduction targets in London if pushed hard (through regulation) or left to the voluntary actions of motor manufacturers and individual choice. There is still a substantial shortfall against the headline target if the higher levels of application are achieved.

\section{INSERT FIGURE 6}

\section{INSERT TABLE 4 AND FIGURE 7}

\section{PP1 Low Emission Vehicles}

Looking in more detail at the individual policy packages within the techno-optimist user role, it is evident that there are a number of potential policy pathways. The take up of low emission vehicles, based largely on hybrid technology, is likely to be very important in reducing $\mathrm{CO} 2$ emissions. It is the single most important intervention as most transport emissions derive from the vehicle fleet. However, an important point, and often overlooked, is that any gains made in terms of greater vehicle efficiencies are likely to be offset by increased vehicle kilometres unless there is complementary behavioural change - i.e. reduced travel distances and mode shift. This is known as the rebound effect.

The types of vehicles currently on the market in the UK are shown in Table 5. There is much variation in terms of $\mathrm{CO} 2$ emissions (and specification and price). The current best generations of new vehicles have emissions levels of around $100 \mathrm{~g} / \mathrm{km}$ (the VW Polo Diesel emits $99 \mathrm{~g} / \mathrm{km}$ and Toyota Prius Hybrid emits $104 \mathrm{~g} / \mathrm{km}$ ). The intention with technological improvements is to push hard to reduce these levels even further. The current (2006) UK car fleet average emissions is $181 \mathrm{~g} / \mathrm{km}$ (from $196 \mathrm{~g} / \mathrm{km}$ in 1997), whilst the new 2006 car fleet average is $167 \mathrm{~g} / \mathrm{km}$ (from $190 \mathrm{~g} / \mathrm{km}$ in 1997). Light goods vehicles emit slightly more CO2, averaging around $182 \mathrm{~g} / \mathrm{km}$ in and heavy goods vehicles (fully loaded) in the order of 1,100 $\mathrm{g} / \mathrm{km}$ (SMMT, 2006). 


\section{INSERT TABLE 5}

An ambitious application of this policy package results in the car fleet averaging around $100 \mathrm{~g} / \mathrm{km}$ by 2025, and this in turn requires a full range of fuel efficient vehicles to become available and for purchasing patterns to change. Government needs to develop and implement a range of incentives to encourage increases in fuel efficient vehicle penetration rates. Because of the difficulties in delivering low emission vehicles to the mass market, reliance on this policy package may be high risk as there is no guarantee that low emission vehicles will penetrate the market to any great degree. The current consumer trend is for higher specification and heavier vehicles, which emit more carbon.

Bearing in mind these current trends and consumer preferences, a less ambitious application of this policy package may be more realistic in scenario testing. A low level of application of this policy package may therefore aim for a car fleet averaging at around $150 \mathrm{~g} / \mathrm{km}$ by 2025 . The results of different levels of application of this policy package vary widely. The high intensity application of PP1 results in a reduction of CO2 contributing proportionately to around $40 \%$ of the total target and the low intensity application of PP1 results in a reduction of $8 \%$ of the total target. This PP is central to the achievement of substantial $\mathrm{CO} 2$ emissions reductions in transport.

\section{PP2 Alternative Fuels}

Additional benefits can be obtained if alternative fuels are used in conjunction with petrol or diesel-electric hybrids. There are many possible alternative fuels on the market - including compressed natural gas, liquid petroleum gas, biofuels (methanol, ethanol, biodiesel) and hydrogen. Many alternative fuels can be used on their own, and others can be blended with existing fuels and used in vehicles without any major modifications to the engines. The International Energy Agency (2004) is ambitious in suggesting that that, by 2030 , some $20-40 \%$ of all fuels in transport could come from alternative sources, mainly biofuels. Recent estimates have been more sceptical about the potential for take up, particularly on a mass market scale (Di Lucia and Nilsson, 2007; Comyns, 2006; and others). There are several options available, but all have limitations in terms of the scale of energy required and in the competing uses for the energy. Options include battery vehicles using renewable energy, the different types and generations of biofuels, natural gas and hydrogen from a range of different sources (Bomb et al., 2007; Jacobsen, 2008).

The Renewable Transport Fuel Obligation (RTFO) requires the UK to achieve a 5\% target for all road vehicle fuels sold on forecourts to be supplied by renewable sources by 2010. The EU biofuels directive as amended (EC, 2003; CEU, 2007) aims for $10 \%$ of biofuels by 2020. It appears that these targets will not be met due to the difficulties in applying fuel technologies to the mass market. Current levels of renewable fuel usage are only $2-3 \%$.

The theoretical levels of potential application for this policy package are again high/medium/low. An optimistic assumption is that alternative fuels have a successful penetration of the fleets to the following proportions - car (35\%), freight (40\%) and bus (90\%). A less optimistic assumption is that alternative fuels are slow to enter the market, with penetration rates at car (0\%), freight (5\%) and bus (5\%). The high intensity application of PP2 results in a reduction of $\mathrm{CO} 2$ contributing $13 \%$ to the total target. The low intensity application of PP2 results in a contribution of $0.5 \%$ to the total target. 
The recent scepticism concerning the likely role of biofuels and wider alternative fuels means that the low intensity application of PP2 is likely to be most realistic.

\section{PP7 Information and Communications Technology (ICT)}

The final major technological policy lever within the techno-optimist role is in applying ICT to reduce emissions in transport and from transport. Measures in transport are targeted at personal and freight travel, and include advanced route and parking guidance, car sharing, public transport information systems, freight logistics and local traffic regulation. The take up of teleactivities are also encouraged.

The scope for $\mathrm{CO} 2$ reduction may be limited. The likelihood is that as levels of communication rise, a complex adaptation of social interaction patterns rather than a simple substitution takes place. There may also be rebound effects as ICT encourages more, not less, travel. If society changes markedly in the future - along the lines of the "network society" vision (Castells, 2000; Hall and Pain, 2006) - then there is a possibility that changes in travel behaviour will help to reduce $\mathrm{CO} 2$ emissions, with a much larger proportion of activities carried out electronically. The techno-optimist role however assumes a medium intensity of application for PP7. The result for a medium level application of PP7 is a contribution reduction in $\mathrm{CO} 2$ of just $1 \%$ of the total target.

Comment - Under the techno-optimist role, the full range of PPs are not used to their full potential. A BAU application is therefore assumed, with a 'limited effort' across the remaining packages. This includes the current congestion charging scheme and some major public transport investment. But even with these levels of investment and the need for dramatic increases in small fuel efficient vehicles, perhaps using alternative fuels, little real progress is made towards achieving the 2025 targets unless substantial incentives are introduced and car purchasing patterns change significantly. Relying on a narrow range of measures means that application has to be very successful to see any progress towards $\mathrm{CO} 2$ emission reduction. Even with a very successful application the full target is not achieved.

\subsection{Complacent Car Addiction}

This user cohort does not see any problems with car use, nor the point in reducing travel by car. They do not attempt to limit their annual growth in travel and show low participation in non-car means of travel. They exhibit the highest levels of car dependency, and they feel strongly about an individual's right to use a car, showing little interest in behavioural change or in technological change (Anable, 2005). Average car fleet emissions rise (to $220 \mathrm{~g} / \mathrm{km}$ ) as people buy higher specification cars. The group believe a $\mathrm{CO} 2$ reduction target should be achieved in the non-transport sectors. This user role results in a contribution reduction in $\mathrm{CO} 2$ of $+11.1 \%$ of the total target, hence moving in the opposite direction to that required.

\section{INSERT FIGURE 8}

\section{INSERT TABLE 6}

Comment - This outcome is the most problematic as transport makes no contribution to the targets, with higher emissions and larger vehicles. In one sense, this is what has happened in the recent past with little reduction in $\mathrm{CO} 2$ emissions and the tendency for many to purchase larger, heavier and more powerful vehicles. 


\subsection{Concerned Realism}

The final user role discussed here is to take a more pragmatic approach and use all policy levers available to the full potential. There is, however, realism within the simulation, reflecting that implementation may not be as successful as expected. This limits the $\mathrm{CO} 2$ reduction potential of this scenario. If there is a strong trend against a certain policy package take up, then the scenario assumptions can reflect these difficulties.

The concerned realist user role envisages a deep reduction in $\mathrm{CO} 2$ emissions will only result if large gains are achieved from both technological and behavioural change. Users have high concern for the negative effects of car use, and believe that urban liveability and lifestyles will improve if public transport, walking and cycling are used to a much greater degree. They are concerned that we will not achieve the forecast gains in technology and behavioural change. They see holding vehicle $\mathrm{km}$ (at present levels), with large gains from technology, as the best way to achieve $\mathrm{CO} 2$ reduction targets. The user role makes better progress towards the required $60 \%$ reduction target (against $\mathrm{BAU}$ ), over half of the aspiration, to $31.8 \% \mathrm{CO} 2$ emission reduction. Some scepticism is introduced concerning expected $\mathrm{CO} 2$ reduction impacts, particularly on the implementation of low emission vehicles and alternative fuels. Deeper reductions in transport $\mathrm{CO} 2$ emissions are however required, suggesting that we need to very closely examine the means and incentives for improving the high intensity application of all available measures.

\section{INSERT FIGURE 9}

\section{INSERT TABLE 7}

\section{PP1 Low Emission Vehicles}

As previous, a relatively low intensity application of this policy package is envisaged as more realistic, bearing in mind current rates of technological penetration.

\section{PP2 Alternative Fuels}

As previous, a low intensity application of this policy package is envisaged as more realistic, bearing in mind the recent concern over the role of biofuels and alternative fuels more generally.

\section{PP3 Pricing Regimes}

Congestion charging or area-wide road pricing could potentially make a substantial difference to $\mathrm{CO} 2$ emissions on a London-wide scale. The BAU application assumes the current congestion charge scheme (with the western extension) is operated. Road pricing could be operated for the whole of London as part of a UK-wide scheme, and also on an environmental basis (i.e. the charging relates to the carbon emissions profile of the vehicle and the number of passengers). This would give clear signals to consumers to switch to more efficient cars or to other modes of transport. There are political difficulties with implementing this package. The concerned realist package assumes some progress, with a congestion charge scheme applied on an area-wide basis across London (most likely as a distance-based charge) and a medium application of parking charging.

\section{PP4: Public Transport}

Public transport investment is critical in allowing consumers to choose carbon efficient means of travel. There is already an extensive public transport network in London, with 
huge investment plans in Transport 2025 (TfL, 2006). The BAU application assumes that the Reference Case (Scenario 1) in T2025 is implemented. This is broadly all currently funded projects, but not including Crossrail. It therefore includes capacity and frequency upgrades on the Underground, National Rail and Docklands Light Railway. More investment could be considered, as represented in Scenario 4 in T2025, or even beyond. This might include Crossrail and potentially wider schemes such as Crossrail 2 (a north-south pan-London link), additional tram routes and demand responsive public transport in the suburbs. The concerned realist package assumes a medium intensity investment in public transport (T2025 Scenario 4, Full Programme) and a medium level of fare reduction.

\section{PP5 Walking and Cycling}

Similarly, investment in walking and cycling facilities and in the streetscape and public realm makes carbon efficient means of travel more attractive, particularly for short journeys. There is already a fairly extensive walking and cycling network in London, yet aggregate walking and cycling mode shares remain low relative to the best examples in Europe. The BAU application assumes that the Reference Case (Scenario 1) in T2025 is implemented, with the current funded walking and cycling projects being implemented. The concerned realist package assumes a medium intensity investment in walking and cycling (T2025 Scenario 4, Full Programme) - a higher level of investment than BAU.

\section{PP6 Urban Planning}

This package focuses on using urban form to support sustainable transport, with efforts directed at both strategic and local scales. Strategically, urban structure is used to support public transport use through higher density development being clustered around an upgraded public transport system. More locally, urban areas are masterplanned to vastly improve their urban design quality, attractiveness for living and working. There is complementary heavy investment in walking and cycling facilities and streetscape design. The BAU application assumes that the Reference Case (Scenario 1) in T2025 is implemented. This represents the urban strategy of the London Plan (GLA, 2004), where some polycentric increases of densities take place, with most effort made in central London, and some investment in improved streetscapes, again mostly in central London. The concerned realist package assumes a medium intensity application of urban planning to reduce travel $\mathrm{CO} 2$ emissions (London Plan+).

\section{PP7: ICT}

As previous, the scope for $\mathrm{CO} 2$ reduction from this package seems limited. A complex adaptation of social interaction is more likely than a simple substitution. The concerned realist package assumes a medium intensity application of ICT however the impacts are not great in terms of transport $\mathrm{CO} 2$ reduction.

\section{PP8 'Smarter Choice' Soft Measures}

This option includes investment in workplace and school travel plans, personalised travel planning programmes and future changes in car ownership (including leasing and car clubs), car sharing and travel awareness initiatives. These are important supporting measures to other packages, but they also have an important impact on reducing $\mathrm{CO} 2$ emissions in their own right. The BAU application assumes that the Reference Case (Scenario 1) in T2025 is implemented. This broadly represents all funded projects. There is more potential if funds were made available for a greater intensity of application of this package. The concerned realist package however assumes a 
medium intensity application of soft measures to reduce travel $\mathrm{CO} 2$ emissions, reflecting that impacts may be less than often forecast due to diminished returns when spread beyond the initial enthusiastic take up.

\section{PP9 Slower Speeds and Ecological Driving}

This option has the potential for substantial immediate and long term benefits if take up is high in terms of reduced speeds and changed driving styles. Slower speeds have the potential to provide extensive savings with some $15-20 \%$ reduction in $\mathrm{CO} 2$ emissions if a maximum speed limit of $80 \mathrm{~km} / \mathrm{hr}$ is introduced on motorways and trunk roads, with lower speeds on other roads such as residential roads. Effective compliance is a critical issue and is likely to impact on end $\mathrm{CO} 2$ reduction impacts. Although the fuel use and speed value curves for new cars are flatter than those for older cars, there are still considerable fuel savings from lower speeds.

Lower speeds need to be combined with awareness programmes and better driving techniques to reduce fuel use. Ecological driving skills have been developed in the Netherlands and elsewhere, and include simple measures such as driving at moderate speeds, avoiding excessive acceleration and harsh braking, changing gears at low engine revolutions, driving in the highest comfortable gear at any given speed, avoiding unnecessary use of in-car equipment (especially air conditioning), keeping tyres inflated and reducing unnecessary loads.

The BAU application assumes that speed limits remain the same and there is little funding of these types of driver skill projects. There is therefore more potential if funds were made available for a greater intensity of application of this package. The concerned realist package assumes a medium intensity application of this package to reduce travel $\mathrm{CO} 2$ emissions. However, the impacts are less than often expected due to enforcement difficulties.

\section{PP10 Long Distance Travel Substitution}

There is some limited potential for long distance travel substitution of rail to air (e.g. Eurostar) but the savings here are not likely to be substantial. Only travel within the London boundary is considered, hence the longer journey effects are not included. The BAU application assumes that only existing high speed train services operate. There would be more potential if a network of services was built. The concerned realist package assumes a medium intensity application of this package; however the $\mathrm{CO} 2$ reduction impacts remain small.

\section{PP11 Freight Transport}

Freight transport is covered tangentially in several of the other policy packages, but this package concentrates on the freight sector as a whole with a series of measures targeted at reducing $\mathrm{CO} 2$ emissions. Different applications of the policy package draw from changed handling factors (the number of links in the supply chain), reduced length of haul, improved rail mode share, reduced empty running, improved fuel efficiency and choice of fuel/power source (McKinnon, 2007a). Subsidiarity (local production and knowledge transfer) and dematerialisation (miniaturisation, advanced logistics and distribution networks, load matching and material consumption) can also lead to savings, some substantial. The BAU application again assumes a limited effort in this area. There is much greater potential on offer if a concerted effort is made in this area (McKinnon, 2007b). The concerned realist package assumes a medium intensity application of the package; however the $\mathrm{CO} 2$ reduction impacts remain small. 
Comment - Even here, with a more compliant set of concerned realist users, it is impossible to achieve the headline targets. Possibilities for more effective achievement are mainly concerned with vehicle emission technologies, and a 'high' application over the range of policy measures. Overall, there is a mismatch between the potential for various policy packages and the willingness of even the concerned realist to engage in substantial behavioural change that would in turn lead to a deep reduction in $\mathrm{CO} 2$ emissions in London.

\subsection{Conclusions}

The potential for greater emission reduction seems to be present, but this is dependent on a level of application of policy measures that does not appear realistic based on current trends. Even with substantial investment in fuel efficient vehicles and substantial behavioural change, as represented in the concerned realist cohort, more is required. A high intensity level of application of virtually all of the policy measures is required to achieve the $60 \%$ target by 2025 . High levels of application of all PPs requires strong political leadership and the support of businesses and people in London. Such commitment has not been found in any of the user groups that have engaged with the TC-SIM analysis. The main conclusion here is that it is extremely difficult to meet the targets and it is even harder to get the full engagement of all interested parties in recognising the nature and scale of the changes required.

\section{International Air Travel and Enabling Mechanisms}

The one policy package not included in any of the scenarios outlined earlier is international air travel. Air travel has been growing at a rate of $6 \%$ per annum (doubling every 12 years). Two problems are evident. One relates to how international aviation should be accounted for in the London targets, as at present they are either excluded (as in most transport planning analysis concerning this topic), or they could be considered as contributing half the full international aviation $\mathrm{CO} 2$ emissions (as suggested in the CCAP; GLA, 2007). The problem is either one of omission or one of dealing with large numbers, as the potential for growth in this sector over the next 2040 years is likely to exceed all other transport related emissions. The second problem is that at present there are very few technological opportunities available, and many of the planes flying today will still be in use in $\mathbf{2 0 2 5}$ and even 2050 (for example, the new A380). The only way to reduce demand is through pricing, regulation and even rationing (Personal Carbon Allowances - PCAs). It is very difficult to deliver a fair outcome that is acceptable in both political and public terms.

TC-SIM can be used to illustrate some of the impacts, including adding international air travel into the calculations, and this provides a means to discuss the difficult issues involved. The simulation can also consider likely options to reduce growth projections for international air travel, including reductions in the demand for particular types of journey (largely through awareness initiatives and price signals), reducing supply (largely through restricting airport growth), and switching to high speed rail (PP10).

Adding the $\mathrm{CO} 2$ emissions associated with London's residents' international air travel to the baseline and target within TC-SIM means that the baseline BAU in 2025 is increased by an additional $35 \mathrm{MtCO} 2$. The previous concerned realist package selection (Section 4.4) achieved a 31.8\% reduction in transport $\mathrm{CO} 2$ emissions, and if international air emissions are considered, this contribution decreases to a $7.7 \%$ reduction in transport $\mathrm{CO} 2$ emissions. A medium level intervention to reduce the 
demand for air travel, through no increase in airport capacity, means that a greater reduction in $\mathrm{CO} 2$ emissions is possible, up to a $11.0 \%$ reduction in transport $\mathrm{CO} 2$ emissions in aggregate.

Comment - There may need to be strong links to enabling mechanisms, such as carbon rationing, to significantly reduce $\mathrm{CO} 2$ emissions from aviation. If international air travel is allowed to continue its upward growth, then the effort in reducing $\mathrm{CO} 2$ emissions from ground transport (and beyond transport) needs to be much greater. The evidence from current trends suggests that this is very difficult. The issues relating to London airport capacity are currently under review.

\section{INSERT FIGURE 10}

Further incentives or enabling mechanisms may be required to help achieve the $\mathrm{CO} 2$ reduction targets. Carbon rationing in transport could be introduced through car manufacturers, fuel suppliers, or individual carbon allocations. Each would involve a cap and trade system with an overall level of emissions, probably reducing in volume over time. This enabling mechanism might help achieve high intensity application in the preceding packages. There are substantial implementation difficulties, particularly with personal carbon allowances, and the scheme with most potential would involve businesses rather than individuals (Defra, 2008; EAC, 2008).

The EU Emissions Trading Scheme (EU ETS) is already running, and polluting businesses trade emission permits according to whether they produce more or less pollution than is allowed. The transport sector will be included in this scheme (from 2012), and this may also include international air emissions. The idea is to set a cap on the aggregate level of emissions and trade within this level. Trading is likely to be at the business and/or national level.

Oil price volatility also impacts on travel. Oil price rises, for example, make travel by carbon intensive modes more expensive and reduce demand. Over the past thirty years there has been some stability in oil prices, but recently this has changed with much greater volatility in prices. In June 2008 a barrel of Brent crude oil reached US\$135 (current prices in November 2009 are at US\$77). There is much concern in the literature about the future supply of oil, with estimates for the peaking of oil supply range from "2007-08" to "after 2010" (World Energy Council) and "2025" (Shell). Oil peaking is likely to result in dramatically higher oil prices as suppliers and consumers react to perceived supply shortages (Gilbert and Perl, 2008). The consumer is shielded to a certain extent by the high tax component in the price of petrol and diesel, but if the current levels of tax are maintained (in November 2009, 110p per litre of unleaded petrol incorporated around 70p of tax, including fuel tax and VAT, representing $64 \%$ of the total price), then a large increase in the cost of oil impacts markedly on the price of petrol and diesel.

Oil price rises could therefore dampen the demand for travel and be viewed as an enabling mechanism to help achieve greater gains in low emission technologies and behavioural change. It is more likely that with higher fuels prices, more carbon efficient vehicles would be bought, walking and cycling options adopted and trip distances shortened by locational choices (in homes, workplaces and other activities). Clear signals would be given to industry and consumers to increase efficiencies. Large price increases may help achieve a high intensity application in the preceding packages. 


\section{Conclusions: Towards Optimised Packaging}

This paper has demonstrated a range of pathways towards improvements, some substantial, in carbon efficiency in the transport sector. All represent significant breaks in current trends and are likely be very difficult to implement. A number of conclusions can be drawn:

1. The headline targets adopted in London are very ambitious, representing a $60 \%$ reduction in CO2 by 2025 (on 1990 levels). A transport sector target would also be useful, including some consideration of international emissions (air and shipping) and also some recognition of the difficult allocation issue of overseas manufacturing (say China) but home consumption (UK).

2. Further consideration is also required in terms of understanding synergetic effects between package implementation. The modelling in this paper assumes additive impacts between packages. This may result in double counting in some areas and missed synergies in others.

3. Many previous estimates of $\mathrm{CO} 2$ reduction potential tend to overstate impacts. For example, the take up of low emission vehicles is slower than expected, and the $\mathrm{CO} 2 \mathrm{~g} / \mathrm{km}$ fleet averages are not reducing at the required rate to hit voluntary targets. The use of alternative fuels, particularly biofuels, is in question, and their CO2 reduction potential in transport may be limited (Jacobsen, 2008; Bomb et al., 2007). There are serious concerns over the life cycle emissions and also in the potential for mass market take up (including land take and fuel supply issues).

4. The impacts of behavioural measures may also be prone to overestimation, as there is some likelihood that the initial positive impacts will reduce as the mass market is tackled. Possible rebound effects may be as high as 30\% (Sorrell, 2007). The assumption of successful continued implementation may need close investigation. The history of transport planning suggests this is not likely to happen, hence more realistic assumptions may have to be made, for example assuming an 'optimism bias' factor of some $50 \%$ or so to give a more realistic estimate of the real net benefit from behavioural (and technological) change. This, of course, does not downgrade the importance of these policy measures to $\mathrm{CO} 2$ reduction, but simply warns of the difficulties of successful implementation.

5. The scenario options tested in the VIBAT London study, using TC-SIM, illustrate that a range of entrenched policy positions all mean that it is difficult to achieve the current $\mathrm{CO} 2$ reduction targets for London:

- The free rider user role is only likely to achieve minimal CO2 reduction gains in the order of $4.5 \% \mathrm{CO} 2$ reduction relative to the $\mathrm{BAU}$ in 2025.

- The techno-optimist user role is only likely to achieve reductions of $6.2 \%$ in $\mathrm{CO} 2$ reduction relative to the BAU in 2025. Much more potential however is available here - up to a $24.5 \% \mathrm{CO} 2$ reduction relative to the BAU in 2025 . The $<100 \mathrm{~g} / \mathrm{km}$ car fleet should be developed as a mandatory target for an agreed future year, say 2025 .

- The complacent car addict user role actually increases $\mathrm{CO} 2$ emissions. 
- The concerned realist user role illustrates that we need to act across the full range of policy packages to achieve $\mathrm{CO} 2$ reductions, but the 'realism perspective' dampens likely impacts to around $31.8 \%$. The lesson here is that the focus needs to be on achieving high intensity and successful application across all measures.

6. A number of policy packages are available to help reduce $\mathrm{CO} 2$ emissions. These have gone beyond individual measures and are intended to cover a range of options that together can make a significant impact, and that can be introduced in a mutually supporting way (Section 3 ). These should all be used to their full potential and developed as part of coordinated and integrated implementation packages, but tailored according to particular local requirements, as being demonstrated in London. Getting beyond a 30\% reduction in transport $\mathrm{CO} 2$ emissions will take a major effort in technological and behavioural terms, and there is little sign of this happening as yet.

The current trends mean that the transport sector continues to perform poorly in contributing to cross-sectoral $\mathrm{CO} 2$ reduction targets. The clear message is to work across the broader range of policy packages and at a higher intensity in application. Low emission vehicles and alternative fuel penetration are likely to remain the most important policy levers as they tackle carbon efficiency in the dominant means of travel (the private car). The main difficulty here is in achieving any level of success in penetration to the mass market. The motor industry and government need to develop mechanisms to achieve this, as well as mandatory targets for manufacturers.

There is also much potential in the behavioural measures, including pricing regimes, increased use of public transport, walking and cycling, ecological driving and slower speeds, and more efficient freight transport. Urban planning and smarter choice soft measures, as well as acting in their own right, potentially perform very important roles as supporting measures to other policy packages, enabling higher levels of success in implementation. If international air emissions are included in the debate, then target achievement becomes impossible. The main perceived difficulty on the behavioural side is in the political willingness to introduce effective policy packages, as there are concerns over public acceptability. The means of knowledge dissemination, communication and participation in decision-making and marketing of policy options and futures all need to be addressed. Tools such as TC-SIM, applied to different contexts, could play an important role in testing different options with a range of different users.

There is a need for some form of mechanism or framework that can help in assessing target achievement over time, with a clear linkage between technological penetration and behavioural change requirements. Methods for monitoring progress in moving towards headline targets seem to be rather limited. The development of potential synergetic packages of policy options, the incentives for change, and the locking in of benefits, all need further investigation.

The $\mathrm{CO} 2$ reduction potential is only one of many key policy objectives in London. Efforts should, be made to improve quality of life and wider sustainability goals (including economic, social and environmental dimensions). Carbon efficient transport 
and lifestyles need to be consistent with these wider aspirations. Simulating the options for carbon reduction in London offers some clarity as to likely progress against current policy positions. The focus now should be on optimising policy package options against multiple objectives and in considering the incentives for achieving effective implementation. The scale of the challenge is now very evident; achieving trendbreaking changes is not easy.

Acknowledgements: many thanks to the UrbanBuzz programme (www.urbanbuzz.org) which funded the VIBAT London study - the basis of much of this paper. Also the wider VIBAT London study team who have helped develop the work - Halcrow, Oxford University Transport Studies Unit, Space Syntax, Zupa, Transport for London and the Greater London Authority. The views expressed in this paper are of course from the authors and do not necessarily reflect those of UrbanBuzz, Transport for London or the Greater London Authority. Thanks also to two anonymous reviewers for useful and constructive comments on the paper.

\section{References}

Anable, J. (2005) Complacent car addicts or aspiring environmentalists? Identifying travel behaviour segments using attitude theory. Transport Policy, 12 (1), pp. 65-78.

Ashiru, O. and Hickman, R., (2009) Visioning and Backcasting for Transport in London (VIBAT-London). TC-SIM Modelling Specification and Assumptions. Halcrow and Oxford University for the UrbanBuzz Programme. London.

Banister, D. and Hickman, R. (2009) Techno-optimism: progress towards CO2 reduction targets in transport. A UK and London perspective. International Journal of Sustainable Development, 12 (1), pp. 24-47.

Bell, M.G.H. (2000) A game theory approach to measuring the performance reliability of transport networks. Transportation Research B, 34 (6), pp. 533-545.

Bomb, C., McCormick, C., Deurwaarder, K. and Kaberger, T. (2007) Biofuels for transport in Europe: Lessons from Germany and the UK. Energy Policy, 35, pp. 22562267.

Council of the European Union (CEU) (2007) Council Meeting on Biofuels Directive 2782 Transport, Telecommunications and Energy.

European Community (EC) (2003) Directive 2003/30/EC. Promotion of the use of Biofuels or other Renewable Fuels for Transport.

EU-POSSUM (1997) Development of Transport Policy Scenarios - Images of the Future. Deliverable 2. EC DGVII Strategic Research, Brussels.

Ewing, R., Bartholomew, K., Winkelman, S., Walters, J and Chen, D. (2008) Growing Cooler. Evidence on Urban Development and Climate Change. Washington: Urban Land Institute.

Commission for Integrated Transport (CfIT) (2007) Transport and Climate Change. London: CfIT.

Castells, M. (2000) The Rise of the Network Society. The Information Age: Economy, Society and Culture. Blackwell.

Comyns, A.E. (2006) Biofuels - use with caution. Focus on Catalysts, 8, pp. 1-2.

Department of the Environment, Food and Rural Affairs (Defra) (2008) Estimated emissions of carbon dioxide by IPCC source category, type of fuel and end user: 1970 - 2006. Defra e-Digest Environmental Statistics. 
Department of the Environment, Food and Rural Affairs (Defra) (2006) Climate Change - the UK Programme 2006. London: Defra.

Department of the Environment, Food and Rural Affairs (Defra) (2008) Synthesis report on the findings from Defra's pre-feasibility study into personal carbon trading. London: Defra.

DETR (2000) Climate Change the UK Programme. London: Stationery Office. CM 4913.

Di Lucia, A. and Nilsson, L. J. (2007) Transport biofuels in the European Union: The state of play. Transport Policy, 14 (6), pp. 533-543.

Department for Transport (DfT) (2007) Road Transport Forecasts for England 2007. Results from the NTM. London: DfT.

Department of Trade and Industry (DTI) (2003) Energy White Paper. Our Energy Future - Creating a Low Carbon Economy. DTI. London: Stationery Office.

Energy Saving Trust (EST) (2007) Green Barometer Report. London: EST.

Environmental Audit Committee (EAC) (2008) Personal Carbon Trading, Fifth Report of the EAC, HC565, London: The Stationery Office.

Gilbert, R and Perl, A. (2008) Transport Revolutions: Moving People and Freight without Oil. London: Earthscan.

Greater London Authority (GLA) (2007) Action Today to Protect Tomorrow: The Mayor's Climate Change Action Plan. London: GLA.

Greater London Authority (GLA) (2009) The London Plan. London: GLA.

Hall, P. and Pain, K. (2006) The Polycentric Metropolis. Learning from Mega-City Regions in Europe. London: Earthscan.

Hickman, R. and Banister, D. (2007) Looking over the horizon: Transport and reduced CO2 emissions in the UK by 2030. Transport Policy, 14 (5), pp. 377-387.

Hickman, R., Ashiru, O. and Banister, D. (forthcoming, 2009a) Achieving carbon efficient transport: backcasting from London. Transportation Research Record.

Hickman, R., Ashiru, O., Saxena, S., Bradbury, A. and Banister, D. (2009b) Visioning and Backcasting for Transport in London (VIBAT-London). Study Reports, Stages 1, 2 and 3. Halcrow and Oxford University for the UrbanBuzz Programme. London. Available on: www.vibat.org.

International Energy Agency (IEA) (2004) Energy Technologies for a Sustainable Future. Paris: IEA.

Intergovernmental Panel on Climate Change (IPCC) (2001) The IPCC Third Assessment Report on Climate Change. Geneva: IPCC.

Intergovernmental Panel on Climate Change (IPCC) (2007) The IPCC Fourth Assessment Report on Climate Change. Geneva: IPCC.

Jacobsen, M.Z. (2008) Effects of ethanol (E85) versus gasoline vehicles on cancer and mortality in the US. Environmental Science and Technology 41 (11), pp. 4150-4157.

Mackay, D.J.C. (2009) Sustainable Energy - Without the Hot Air. Cambridge: UIT.

Mann, M. E.; Bradley, R.S. and Hughes, M.K. (1998), Global-scale temperature patterns and climate forcing over the past six centuries. Nature, 392, pp. 779-787.

McKinnon, A (2007a) Decoupling of road freight transport from economic growth trends in the UK: An exploratory analysis. Transport Reviews 27 (1), pp. 37-65.

McKinnon, A. (2007b) CO2 emissions from Freight Transport in the UK, Report 
prepared for the Climate Change Working Group of the Commission for Integrated Transport.

Organisation for Economic Co-operation and Development (OECD) (2000) EST! Environmentally Sustainable Transport. Futures, Strategies and Best Practice. Synthesis Report. Paris: OECD.

Royal Commission on Environmental Pollution (RCEP) (1994) Transport and the Environment, 18th Report. Cm 2674. London: HMSO.

Royal Commission on Environmental Pollution (RCEP) (1997) Transport and the Environment - Developments since 1994, 20th Report. Cm 3752. London: Stationery Office.

Fontaras, G., Pistikopoulos, P. and Samaras, Z. (2008) Experimental evaluation of hybrid vehicle fuel economy and pollutant emissions over real-world simulation driving cycles. Atmospheric Environment, 42 (18), pp. 4023-4035.

Samaras Z., Zachariadis, T., Joumard, R., Vernet, I., Hassel, D., Weber, F.-J. and Rijkeboer, R. (1998) Alternative short tests for inspection and maintenance of in-use cars with respect to their emissions performance. International Journal of Vehicle Design, 20 (1-4), pp. 292-303.

Shiftan, Y., Outwater, M.L., and Zhou, Y. (2008) Transit market research using structural equation modelling and attitudinal market segmentation. Transport Policy 15 (3), pp. 186-195

Schäfer, A., Heywood, J.B., Jacoby, H.D. and Waitz, I.A. (2009) Transportation in A Climate Constrained World. Cambridge, MA: MIT Press.

Society of Motor Manufacturers and Traders (SMMT) (2006) Annual CO2 Report. London: Society of Motor Manufacturers and Traders.

Sorrell, S. (2007) The rebound effect: An assessment of the evidence for economywide energy savings from improved energy efficiency. Sussex Energy Group for the Technology and Policy Assessment function of the UK Energy Research Centre.

Sperling, D. and Gordon, D. (2009) Two Billion Cars. Driving Towards Sustainability. Oxford: Oxford University Press.

Stern, N. (2009) A Blueprint for a Safer Planet. London: Random House.

Transport for London (TfL) (2006) Transport 2025: Transport Vision for a Growing World City. London: TfL.

Transport for London TfL (2009) The Mayor's Transport Strategy. London: GLA/TfL.

Von Neumann, J. and Morgenstern, O. (1944) Theory of Games and Economic Behaviour. Princeton University Press.

Yang, C., McCollum, D., McCarthy, R., and Leighty, W. (2009) Meeting an 80\% reduction in greenhouse gas emissions from transportation by 2050: a case study in California. Transportation Research D, 14: 147-156. 


\section{ANNEX}

Annex 1: T2025 Public Transport Modelling Scenarios

\begin{tabular}{|c|c|}
\hline \multicolumn{2}{|c|}{ Scenario 1: T2025 Reference Case } \\
\hline National Rail & $\begin{array}{l}\text { Channel Tunnel Rail Link to St. Pancras } \\
\text { Chiltern Railways upgrade } \\
\text { Heathrow Express extension to Heathrow Terminal } 5 \\
\text { London Overground phases } 1 \text { and } 2 \text { : East London line extension from Dalston to } \\
\text { West Croydon and Crystal } \\
\text { Palace and Gospel Oak to Barking line upgrade } \\
\text { Rail reliability - increase journey times by } 4.5 \%\end{array}$ \\
\hline LU & $\begin{array}{l}\text { Piccadilly line extension to Heathrow Terminal } 5 \\
\text { PPP line upgrades on Waterloo \& City and Jubilee lines } \\
\text { Reliability - an average } 30 \% \text { drop in capacity and } 10 \% \text { increase in on-train times } \\
\text { on all lines not fully upgraded by March } 2010 \text {, i.e. Victoria, Northern, Piccadilly, } \\
\text { sub surface (Circle, District, Metropolitan, Hammersmith \& City) and Bakerloo } \\
\text { lines }\end{array}$ \\
\hline DLR & $\begin{array}{l}\text { DLR Bank to Lewisham three-car upgrade } \\
\text { DLR extension to Woolwich } \\
\text { DLR Stratford International - Canning Town }\end{array}$ \\
\hline Bus \& Transit & $\begin{array}{l}\text { Bus service increase of } 2.4 \% \text { to be achieved by } 2010 \\
\text { Greenwich Waterfront and East London Transit schemes phase } 1\end{array}$ \\
\hline Other & $\begin{array}{l}\text { Thames Gateway Bridge } \\
\text { Smart transport measures - modest investment assumed } \\
\text { Rail, Tube and bus fares increase by RPI to } 2025\end{array}$ \\
\hline \multicolumn{2}{|c|}{ Scenario 2: Full PPP + Scenario 1} \\
\hline LU & $\begin{array}{l}\text { Full public private partnership (PPP) improvements (Upgrades of Victoria, } \\
\text { Northern, Piccadilly, sub surface (Circle, District, Metropolitan, Hammersmith \& } \\
\text { City) and Bakerloo lines }\end{array}$ \\
\hline \multicolumn{2}{|c|}{ Scenario 3: Crossrail + Scenario 2 (which includes Scenario 1) } \\
\hline National Rail & Crossrail \\
\hline Bus & Increase in bus supply of $20 \%$ from 2006 to 2025 \\
\hline \multicolumn{2}{|c|}{ Scenario 4: Crossrail2 + Scenario 3 (which includes Scenario 2) } \\
\hline National Rail & $\begin{array}{l}\text { Rail 2025: Capacity enhancements to existing lines and } \\
\text { East London line extension from Surrey Quays to Clapham Junction } \\
\text { Thameslink programme } \\
\text { Crossrail } 2\end{array}$ \\
\hline DLR & $\begin{array}{l}\text { DLR capacity enhancement - Poplar to Stratford } \\
\text { DLR extension to Dagenham Dock }\end{array}$ \\
\hline Light Transit & $\begin{array}{l}\text { Thames Gateway bus transit schemes (further phases of Greenwich Waterfront } \\
\text { and East London Transit) } \\
\text { West London Tram and Cross River Tram } \\
\text { Tramlink extensions }\end{array}$ \\
\hline LU & $\begin{array}{l}\text { Northern line segregation of services } \\
\text { Enhanced line upgrades beyond PPP }\end{array}$ \\
\hline Bus & $\begin{array}{l}\text { A further increase in bus supply of } 20 \% \\
\text { (total } 40 \% 2006 \text { to } 2025 \text { ) }\end{array}$ \\
\hline $\begin{array}{l}\text { Congestion and } \\
\text { Emissions Reduction } \\
\text { Plan }\end{array}$ & $\begin{array}{l}\text { A package of measures to reduce congestion and emissions, including smart } \\
\text { transport measures, vehicle technology change, a Climate Change Action Plan } \\
\text { and a national road user charging scheme in London }\end{array}$ \\
\hline Other & Silvertown Link \\
\hline
\end{tabular}

Source: Transport 2025 (TfL, 2006). 